\title{
Th(IV) complexes with cis-ethylenebis(diphenylphosphine oxide): X-ray structures and NMR solution studies
}

\author{
Paul T. Morse, ${ }^{a}$ Richard J. Staples, ${ }^{\mathrm{b}}$ Shannon M. Biros ${ }^{\mathrm{a}^{*}}$ \\ aDepartment of Chemistry, Grand Valley State University, 1 Campus Dr., Allendale, MI 49401; \\ ${ }^{\mathrm{b}}$ Center for Crystallographic Research, Department of Chemistry, Michigan State University, \\ 578 S. Shaw Lane, East Lansing, MI 48824 \\ *Corresponding Author: biross@gvsu.edu (S.M. Biros); Ph: +1-616-331-8955; Fax: +1-616- \\ $331-3230$
}

\begin{abstract}
The complexation of $\mathrm{Th}\left(\mathrm{NO}_{3}\right)_{4}$ with the rigid diphosphoryl ligand cisethylenebis(diphenylphosphine oxide) has been investigated using X-ray crystallography, IR, NMR and CHN analysis. Three crystal polymorphs were grown out of methanolic solution where the 1:3 Th(IV)-ligand complex is ten-coordinate, and the metal is bound by three bidentate ligands and two nitrato groups. An additional metal-ligand complex with similar geometry was also grown from the non-coordinating solvent $\mathrm{CHCl}_{3}$. Analysis of $\mathrm{CD}_{3} \mathrm{OD}$ and $\mathrm{CDCl}_{3}$ solutions of this complex using ${ }^{1} \mathrm{H}$ and ${ }^{31} \mathrm{P}$ NMR reveals that ligand off-rates are fast on the NMR time scale in methanol- $d_{4}$, and slow on the NMR time scale in chloroform- $d$. Further, three additional crystal structures are reported describing the 1:1 and 1:2 Th(IV)-ligand complex, the 1:3 Th(IV)ligand complex with an extra aqua ligand, and a serendipitous 1:3 Th(IV)-ligand structure where one ligand bears an epoxide.
\end{abstract}

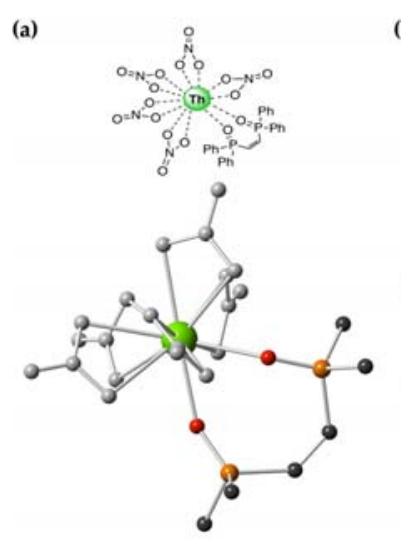

(b)

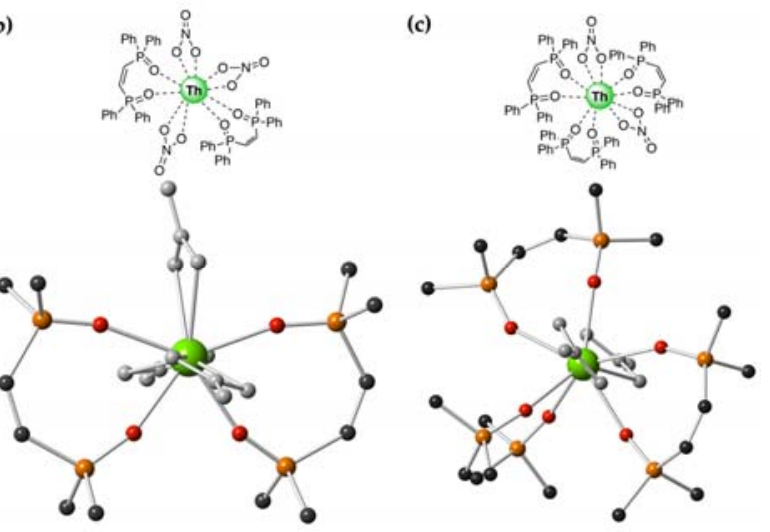

Keywords: actinide; crystal structure; NMR; phosphine oxide 


\section{Introduction}

The coordination chemistry of the actinide thorium continues to gain attention from researchers for uses in catalysis, energy production, and the production of new materials. Thorium is found in small quantities in nearly all rock, soil, and water samples in the form of ${ }^{232} \mathrm{Th}$, its major isotope. Additional isotopes of Th have been identified $\left({ }^{228} \mathrm{Th},{ }^{230} \mathrm{Th},{ }^{234} \mathrm{Th}\right)$, but these are mainly decay products of other man-made radionuclides or from absorption in nuclear reactors. ${ }^{232} \mathrm{Th}$ has a half-life of 14 billion years and emits radiation through a long decay series beginning with an $\alpha$-emission to give ${ }^{228} \mathrm{Ra}$ and ending with the stable isotope ${ }^{208} \mathrm{~Pb}$.

Due in part to its extremely high melting point $\left(3300^{\circ} \mathrm{C}\right), \mathrm{ThO}_{2}$ (aka "thoria") has found applications in light bulb elements, lantern mantles and heat-resistant ceramics.[1,2] It is a component of spent nuclear fuel from uranium-based nuclear reactors, and has itself been explored as an energy source.[3] There has also been a wide variety of reports directed toward the use of Th(IV) complexes as catalysts for chemical transformations.[4] A selection of reactions mediated by Th(IV) organometallic complexes include: $\mathrm{C}-\mathrm{H}$ and $\mathrm{C}-\mathrm{O}$ bond activation, [5, 6] hydrosilylation of alkenes and alkynes,[7] hydroamination,[7-10] aldehyde dimerization,[11] and phosphonoester hydrolysis.[12]

To this end, investigations into the synthesis and structure of high-denticity Th(IV) complexes will contribute to each of the diverse set of chemical areas described above. New organic ligands could find use as sequestering agents for Th(IV) out of nuclear waste streams, provide stereochemical control for catalytic transformations, or generate new thorium containing materials with unique properties. Interestingly, out of the over 750,000 structures in the Cambridge Structural Database[13] only 553 contain coordination complexes of thorium. Of these 553 reported structures, less than 100 are greater than nine-coordinate containing all oxygen donors. The need for additional structural information describing the coordination geometries available to this unique element is strong. We contribute to this area here with seven new crystal structures containing Th(IV) and a rigid, bidentate phosphine oxide ligand. The crystallographic work is accompanied by a complete set of high resolution spectra (IR, ${ }^{1} \mathrm{H}$ and

${ }^{31} \mathrm{P}$ NMR) used to characterize the isolated complex, as well as corresponding elemental analysis (CHN) data. 


\section{Experimental}

\subsection{Materials and measurements}

All chemicals (including deuterated solvents) were purchased from Sigma-Aldrich, Fisher

Scientific, Strem Chemicals, VWR or Acros Chemicals and used without further purification. ${ }^{1} \mathrm{H}$, ${ }^{13} \mathrm{C}$ and ${ }^{31} \mathrm{P}$ NMR spectral data were recorded on a Varian Inova 400 FTNMR spectrophotometer. For ${ }^{1} \mathrm{H}$ and ${ }^{13} \mathrm{C}$ NMR, chemical shifts are expressed as parts per million $(\delta)$ relative to $\mathrm{SiMe}_{4}(\mathrm{TMS}, \delta=0)$, and referenced internally with respect to the protio solvent impurity. For ${ }^{31} \mathrm{P}$ NMR, chemical shifts are expressed as parts per million $(\delta)$ relative to $\mathrm{H}_{3} \mathrm{PO}_{4}$ $(\delta=0)$. IR spectra were acquired neat on a Jasco 4100 FT-IR. Elemental $(\mathrm{CHN})$ analysis of ligand 1 was carried out using a Perkin Elmer 2400 Series II CHNS/O Analyzer. Elemental (CHN) analysis of the Th(IV) complex was performed by Atlantic Microlab Inc., Norcross, GA.

CAUTION!!! Natural thorium (primary isotope ${ }^{232} \mathrm{Th}$ ) is a weak $\alpha$-emitter (4.012 MeV) with a half-life of $1.41 \times 10^{10}$ years; manipulations and reactions should be carried out in monitored fume hoods or in an inert atmosphere drybox in a radiation laboratory equipped with $\alpha$ - and $\beta$ counting equipment.

\subsection{Synthesis of ligand 1}

For the preparation of ligand 1, a slightly modified procedure of that described by Daigle and coworkers[14] was followed, and the ${ }^{31} \mathrm{P}$ NMR data from Gallagher et al. was used to confirm the stereochemistry of the alkene in the final product.[15] cis-ethylenebis(diphenylphosphine) (0.250 $\mathrm{g}, 0.631 \mathrm{mmol})$ was dissolved in tetrahydrofuran $(2.50 \mathrm{~mL})$ at $290 \mathrm{~K}$. To this solution, $30 \% \mathrm{H}_{2} \mathrm{O}_{2}$ $(0.25 \mathrm{~mL})$ was added drop wise with stirring over 5 minutes while keeping the solution chilled in an ice bath under an inert atmosphere of nitrogen gas. The ice bath was removed 20 minutes after completion of the addition, and the reaction was allowed to stir for an additional 2 hours. The resultant white slurry was placed in a crystallization dish for 24 hours to facilitate solvent evaporation. The crude product was recrystallized from boiling benzene $(125 \mathrm{~mL})$ and dried under reduced pressure for $24 \mathrm{~h}$ to yield cis-ethylenebis(diphenylphosphine oxide) (cis-dppeO $\left.\mathrm{d}_{2}\right)$ 1 as a white solid (0.178 g, 71\% yield). ${ }^{1} \mathrm{H}$ NMR (400 MHz, $\left.\mathrm{CDCl}_{3}\right): \delta 7.72-7.64(\mathrm{~m}, 8 \mathrm{H}), 7.49$ $7.42(\mathrm{~m}, 4 \mathrm{H}), 7.40-7.18(\mathrm{~m}, 10 \mathrm{H}) ;{ }^{13} \mathrm{C} \mathrm{NMR}\left(100 \mathrm{MHz}, \mathrm{CDCl}_{3}\right): \delta 143.3\left(\mathrm{dd}, J_{C P}=3.0,95 \mathrm{~Hz}\right.$, 
$\left.\mathrm{C}_{\text {ipso }}\right), 132.7\left(\mathrm{dd}, J_{C P}=4.0,110 \mathrm{~Hz}, \mathrm{C}=\mathrm{C}\right.$ alkene), $132.0\left(\mathrm{~s}, \mathrm{C}_{\text {para }}\right), 131.6\left(\mathrm{dd}, J_{C P}=5.0,6.0 \mathrm{~Hz}\right.$, $\left.\mathrm{C}_{\text {meta }}\right) ;{ }^{31} \mathrm{P}$ NMR (162 MHz, $\left.\mathrm{CDCl}_{3}\right): \delta 21.6(\mathrm{~s}) ;{ }^{1} \mathrm{H}$ NMR (400 MHz, $\left.\mathrm{CD}_{3} \mathrm{OD}\right): \delta$ 7.71-7.63 (m, $8 \mathrm{H}), 7.62-7.49(\mathrm{~m}, 5 \mathrm{H}), 7.52-7.32(\mathrm{~m}, 9 \mathrm{H}) ;{ }^{31} \mathrm{P} \mathrm{NMR}\left(162 \mathrm{MHz}, \mathrm{CD}_{3} \mathrm{OD}\right): \delta 23.2(\mathrm{~s}) ; \mathrm{mp}=228-$ $230{ }^{\circ} \mathrm{C}$, IR (neat) $v=1490,1434(\mathrm{C}=\mathrm{C}), 1173(\mathrm{P}=\mathrm{O}) \mathrm{cm}^{-1}$; Anal. calcd. for $\mathrm{C}_{26} \mathrm{H}_{22} \mathrm{O}_{2} \mathrm{P}_{2}$ (found): C, 72.89 (72.58); H, 5.18 (4.89); N, 0.00 (0.03).

\subsection{Synthesis of 1:3 Th-ligand 1 complex}

cis-dppeO 1 ( $10.100 \mathrm{~g}, 0.252 \mathrm{mmol})$ was dissolved in $\mathrm{MeOH}(15.0 \mathrm{~mL})$ at $290 \mathrm{~K}$. To this solution, thorium(IV) nitrate hydrate $(0.037 \mathrm{~g}, 0.078 \mathrm{mmol})$ was added. The mixture was stirred for $24 \mathrm{~h}$ until it became a homogenous solution. The volatiles were removed via rotary evaporation and dried via Schlenk line for $24 \mathrm{~h}$ to yield the resultant complex, $\mathrm{Th}\left(\mathrm{NO}_{3}\right)_{2}$ -

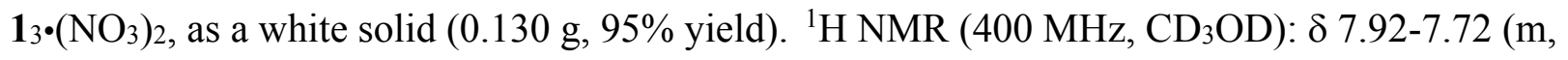
2H), 7.71-7.35 (m, 14H), 7.27-7.15 (m, 6H); ${ }^{31} \mathrm{P}$ NMR (162 MHz, CD $\left.\mathrm{CD}_{3} \mathrm{OD}\right): \delta 31.7$ (s); ${ }^{31} \mathrm{P}$ NMR $\left(162 \mathrm{MHz}, \mathrm{CDCl}_{3}\right): \delta 33.9(\mathrm{~s}), 31.5(\mathrm{~s}), 21.5(\mathrm{~s}) ; \mathrm{IR}$ (neat) $v=1496,1438(\mathrm{C}=\mathrm{C}), 1141(\mathrm{P}=\mathrm{O})$ $\mathrm{cm}^{-1}$; Anal. calcd. for $\mathrm{C}_{78} \mathrm{H}_{66} \mathrm{~N}_{4} \mathrm{O}_{18} \mathrm{P}_{6} \mathrm{Th} \cdot 4.5 \mathrm{H}_{2} \mathrm{O}$ (found): $\mathrm{C}, 50.74$ (50.63); $\mathrm{H}, 4.09$ (4.09); N, $3.03(3.21)$.

\subsection{Crystal structure determination and refinement}

Data were collected using a Bruker CCD (charge coupled device) based diffractometer equipped with an Oxford Cryostream low-temperature apparatus operating at $173 \mathrm{~K}$. The total number of images was based on results from the program COSMO[16] where redundancy was expected to be 4.0 and completeness of $100 \%$ out to $0.83 \AA$. Cell parameters were retrieved using APEX II software[17] and refined using SAINT on all observed reflections. Data reduction was performed using the SAINT software,[18] which corrects for Lp. Scaling and absorption corrections were applied using SADABS[19] multi-scan technique, supplied by George Sheldrick. The structures were solved either by the direct method or the Patterson Expansion method using the SHELXS-97 program and refined by least squares method on $\mathrm{F}^{2}$, SHELXL97,[20] which are incorporated in OLEX2.[21, 22] All non-hydrogen atoms are refined anisotropically. Hydrogens were calculated by geometrical methods and refined as a riding model. The crystals used for the diffraction study showed no decomposition during data collection. Further crystallographic data and experimental details for structural analysis of all the 
complexes are summarized in Tables 2, 4 and 7, and selected bond lengths and angles with their estimated standard deviations are given in Tables 3, 5, 6, 8 and 9. Complete tables for each structure reported here, along with diagrams depicting the thermal ellipsoids at $50 \%$, are provided in the supporting information.

\section{Results and discussion}

\subsection{Synthesis of the ligand and 1:3 Th-ligand complex}

The organic ligand involved in this study, cis-ethylenebis(diphenylphosphine oxide) (1), was prepared following standard procedures with stoichiometric oxidation of the starting phosphine using hydrogen peroxide (Scheme 1). The synthesis, IR and ${ }^{1} \mathrm{H}$ NMR characterization of this compound was reported by Daigle and co-workers,[14] and its X-ray crystal structure determined by Omondi et al.[23] In our hands, we noticed a small amount of trans-isomer as a byproduct from the oxidation reaction. The desired cis-isomer 1 was readily purified, however, by recrystallization from hot benzene to give the product as a white powder in good yield.

Ligand 1 was characterized using ${ }^{1} \mathrm{H},{ }^{13} \mathrm{C}$ and ${ }^{31} \mathrm{P} \mathrm{NMR}$, as well as IR, melting point and $\mathrm{CHN}$ analysis. Due to the similar electronic environment of the vinyl and aromatic hydrogen atoms in ligand $\mathbf{1}$, and further complicated by extensive ${ }^{1} \mathrm{H}-{ }^{31} \mathrm{P}$ coupling, the ${ }^{1} \mathrm{H}$ NMR spectrum of this compound is not a first order spectrum and thus the assignment of the hydrogens to the observed signals is not trivial. The ${ }^{13} \mathrm{C}$ and ${ }^{31} \mathrm{P}$ NMR spectra, however, are straightforward to interpret with the ${ }^{31} \mathrm{P}$ data being especially useful in the confirmation of the cis- vs. transisomers as described by Duncan and Gallagher.[15]

Based on other Th(IV) structures in the literature with bidentate ligands, we proposed that there would be room for three bidentate ligands $\mathbf{1}$ in the first coordination sphere of the thorium center. To this end, we prepared the 1:3 Th-1 complex by stirring three molar equivalents of ligand 1 with $\mathrm{Th}\left(\mathrm{NO}_{3}\right)_{4} \bullet$ hydrate in methanol. Evaporation of the volatiles under reduced pressure gave the desired complex as an air-stable white powder in nearly quantitative yield (Scheme 1). The obtained solid was characterized by $\mathrm{CHN}$ analysis, IR, ${ }^{1} \mathrm{H}$ and ${ }^{31} \mathrm{P} \mathrm{NMR}$, and $\mathrm{X}$-ray crystallography. 

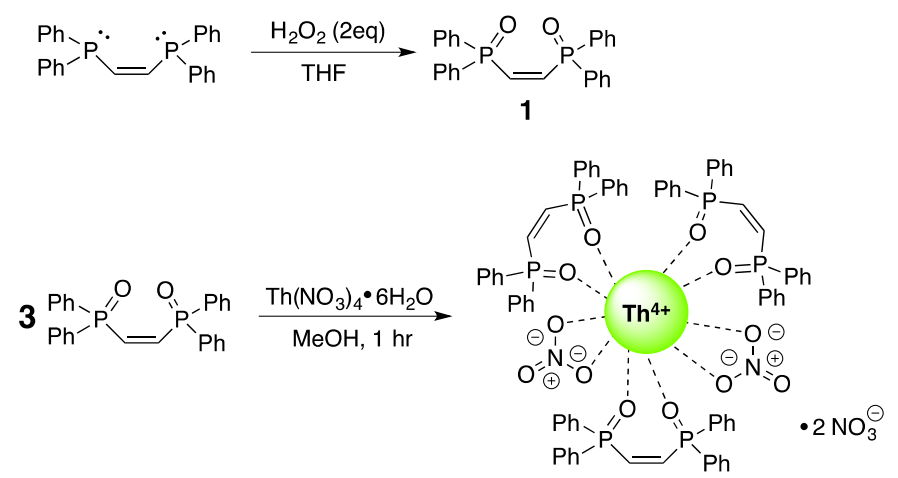

Scheme 1. Synthesis of ligand 1 and the $1: 3\left[\mathrm{Th}\left(\mathrm{NO}_{3}\right)_{2}-\mathbf{1}_{3} \cdot\left(\mathrm{NO}_{3}\right)_{2}\right]$ complex.

\subsection{NMR and IR studies}

Confirmation of metal-complexation can be readily assessed by the IR spectrum of the Th-1 complex (Table 1 and Supporting Information). The phosphoryl $\mathrm{P}=\mathrm{O}$ stretch of the complex is shifted to lower wavenumbers from free 1 by approximately $30 \mathrm{~cm}^{-1}$, indicating chelation of the donor oxygen atoms to the metal center. The stretches corresponding to vinyl and aryl $\mathrm{C}=\mathrm{C}$ bonds broaden, but shift only slightly upon complexation. Further examination of the IR spectrum provides information about the environment and binding geometry of the nitrate counter ions present from the $\mathrm{Th}\left(\mathrm{NO}_{3}\right)_{4}$ salt used in the preparation. The binding mode of inner sphere nitrato groups can be identified as monodentate or bidentate based on the peak separation of relevant stretches at $\sim 1450\left(v(\mathrm{~N}=\mathrm{O})\right.$ and $\sim 1300 \mathrm{~cm}^{-1}\left(v_{\text {symm }}\left(\mathrm{NO}_{2}\right)\right)$. [24-26] For this $\mathrm{Th}\left(\mathrm{NO}_{3}\right)_{2-}$ $1_{3} \cdot\left(\mathrm{NO}_{3}\right)_{2}$ complex, nitrate stretches appear at 1437 and $1296 \mathrm{~cm}^{-1}$ (Table 1). The peak separation of $141 \mathrm{~cm}^{-1}$ strongly suggests that at least one inner-sphere nitrate is bound to the Th(IV) metal center in a bidentate fashion in the solid state. Stretches for the purely ionic outer sphere nitrates can also be identified in the IR spectrum at $1396 \mathrm{~cm}^{-1}$. This analysis is further supported by the X-ray crystal structure (vide infra). 
Table 1. Infrared absorption bands $\left(\mathrm{cm}^{-1}\right)$ of $c i s-\operatorname{dppEO}(\mathbf{1})$ and the $\mathrm{Th}\left(\mathrm{NO}_{3}\right)_{2}-\mathbf{1}_{3} \cdot\left(\mathrm{NO}_{3}\right)_{2}$ complex.

\begin{tabular}{|c|c|c|c|c|c|c|c|c|}
\hline Compound & $v(\mathrm{P}=\mathrm{O})$ & $v(\mathrm{C}=\mathrm{C})$ & $v(\mathrm{C}=\mathrm{C})$ & $v(\mathrm{~N}=\mathrm{O})$ & $v_{\mathrm{a}}\left(\mathrm{NO}_{2}\right)$ & $v_{\mathrm{s}}\left(\mathrm{NO}_{2}\right)$ & $v(\mathrm{NO})$ & $\begin{array}{c}\text { ionic } \\
\text { nitrate }\end{array}$ \\
\hline $\mathbf{1}$ & 1173 & 1490 & 1434 & - & - & - & - & - \\
\hline $\mathrm{Th}\left(\mathrm{NO}_{3}\right)_{2}-\mathbf{1}_{3} \cdot\left(\mathrm{NO}_{3}\right)_{2}$ & 1141 & 1496 & 1438 & 1437 & 1296 & 1027 & 809 & 1396 \\
\hline
\end{tabular}

Solution studies of the $\mathrm{Th}\left(\mathrm{NO}_{3}\right)_{2}-\mathbf{1}_{3} \cdot\left(\mathrm{NO}_{3}\right)_{2}$ complex were carried out by ${ }^{1} \mathrm{H}$ and ${ }^{31} \mathrm{P} \mathrm{NMR}$ in both $\mathrm{CD}_{3} \mathrm{OD}$ and $\mathrm{CDCl}_{3}$ solutions. In $\mathrm{CD}_{3} \mathrm{OD}$ solution, the ${ }^{1} \mathrm{H}$ NMR spectrum of the $\mathrm{Th}(\mathrm{IV})$ complex showed broad signals with complicated splitting patterns similar to the ones observed in the spectrum of free ligand 1 (Figure 1). Interestingly, an apparent doublet of a doublet appears downfield centered at $\sim 7.8 \mathrm{ppm}$ bearing a large coupling constant $(\sim 30 \mathrm{~Hz})$ consistent with twobond phosphorus-hydrogen splitting. Most likely this signal corresponds to the vinylic hydrogens, since they are the closest to the chelating $\mathrm{P}=\mathrm{O}$ groups of the ligand. It is difficult to make conclusive signal assignments from this spectrum owing to the complex nature of the splitting patterns featured by free ligand $\mathbf{1}$. The ${ }^{31} \mathrm{P}\{\mathrm{H}\}$ NMR spectrum of the $\mathrm{Th}\left(\mathrm{NO}_{3}\right)_{2}-$ 13. $\left(\mathrm{NO}_{3}\right)_{2}$ complex displays a sole signal resonating at $30 \mathrm{ppm}(\Delta \delta 8.5 \mathrm{ppm})$ and appearing as a sharp singlet. From the relatively sharp and single signal observed in this ${ }^{31} \mathrm{P}\{\mathrm{H}\}$ spectrum, we suggest that in $\mathrm{CD}_{3} \mathrm{OD}$ solution the chemical exchange process between the ligand occurs at a rate that is fast on the NMR time scale, and the observed broadening in the ${ }^{1} \mathrm{H}$ NMR spectrum is caused by the presence of the Th(IV) metal.

A different picture of the dynamics emerges when the complex $\operatorname{Th}\left(\mathrm{NO}_{3}\right)_{2}-\mathbf{1}_{3} \cdot\left(\mathrm{NO}_{3}\right)_{2}$ is dissolved in the non-coordinating solvent $\mathrm{CDCl}_{3}$. The signals in the ${ }^{1} \mathrm{H}$ NMR spectra are severely broadened and, unfortunately, uninterpretable. The ${ }^{31} \mathrm{P}$ NMR spectrum shows three sharp singlets corresponding to what, we propose, are three different magnetic environments for the phosphorus atoms in the ligands (Figure 1). The signal at $21.5 \mathrm{ppm}$ likely corresponds to free, uncoordinated ligand as this chemical shift is the same as observed for $\mathbf{1}$ alone in $\mathrm{CDCl}_{3}$. The signals at 31.5 and 33.9 ppm likely correspond to metal bound ligands in complexes of different stoichiometry (i.e. 1:2, 1:3).

As to why different ${ }^{31} \mathrm{P}$ NMR spectra are observed for the complex dissolved in these two different solvents, we can employ a relatively simple explanation related to the solvent's role in assisting ligand dissociation. In the case of $\mathrm{CD}_{3} \mathrm{OD}$, the solvent likely aids in the dissociation 
mechanism of the ligand by occupying a metal coordination site when the ligand detaches from the metal. This reduces the energy barrier of the dissociation process, resulting in a time averaged signal for the ligand in both the ${ }^{1} \mathrm{H}$ and ${ }^{31} \mathrm{P}$ NMR spectra. Conversely, in $\mathrm{CDCl}_{3}$ there is no assistance from the solvent in this ligand exchange mechanism and the process slows on the ${ }^{31} \mathrm{P}$ NMR time scale and multiple species can be observed in solution as separated phosphorus signals. The ${ }^{1} \mathrm{H}$ NMR spectrum is difficult to interpret because the multiple species have overlapping signals and interfere with one another.

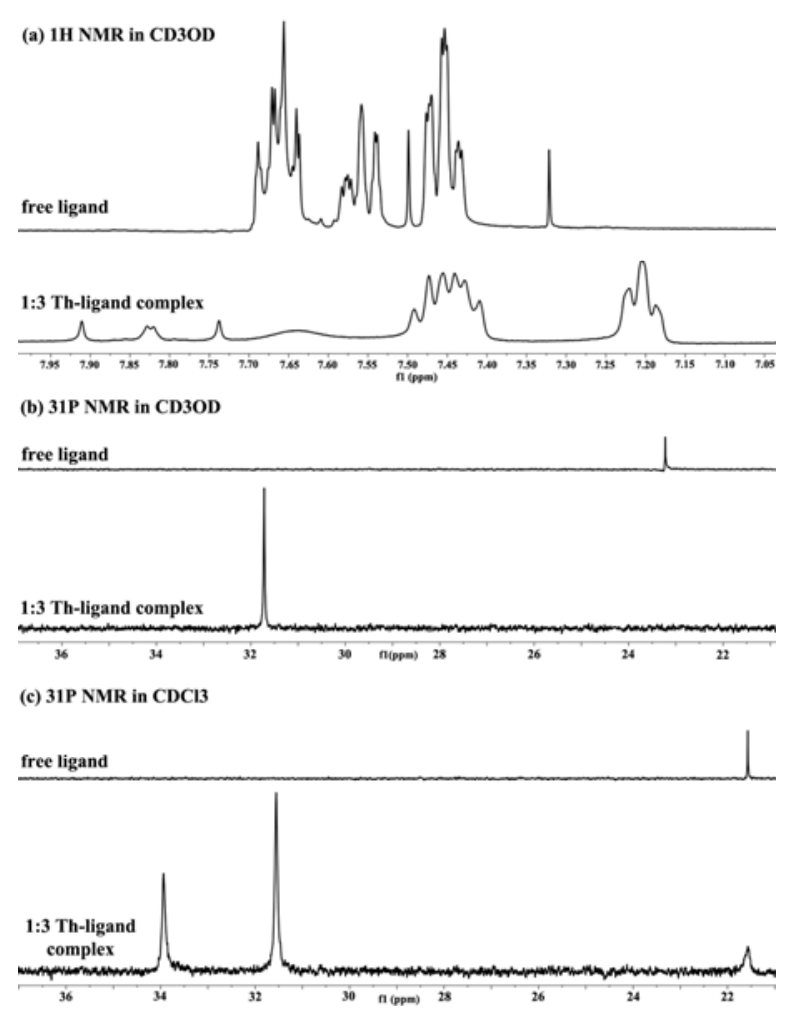

Figure 1. NMR analysis: (a) ${ }^{1} \mathrm{H}$ NMR spectrum (400 MHz) of free ligand (top) and $\mathrm{Th}\left(\mathrm{NO}_{3}\right)_{2}$ 13. $\left(\mathrm{NO}_{3}\right)_{2}$ complex (bottom) in $\mathrm{CD}_{3} \mathrm{OD}$; (b and c) ${ }^{31} \mathrm{P}$ NMR spectrum (162 MHz) of free ligand (top) and $\mathrm{Th}\left(\mathrm{NO}_{3}\right)_{2} \mathbf{1}_{3} \cdot\left(\mathrm{NO}_{3}\right)_{2}$ complex (bottom) in $\mathrm{CD}_{3} \mathrm{OD}$ and $\mathrm{CDCl}_{3}$, respectively.

\subsection{Crystal structures of the complex}

\subsubsection{Crystal structures of the 1:3 Th-ligand complex from $\mathrm{MeOH}$ and $\mathrm{CHCl}_{3}$}

Crystals suitable for X-Ray diffraction of the $\mathrm{Th}\left(\mathrm{NO}_{3}\right)_{2}-\mathbf{1}_{3} \cdot\left(\mathrm{NO}_{3}\right)_{2}$ complex were grown by slow vapor diffusion of benzene into a concentrated solution of the complex in methanol to give structure 2. Alternatively, crystals were also obtained by the vapor diffusion of carbon 
tetrachloride into a concentrated solution of the complex in chloroform to give structure 3 . Crystal structure and refinement data for structures $\mathbf{2}$ and $\mathbf{3}$ is given in Table 2.

Complex 2 crystallized in the triclinic space group P-1. The asymmetric unit consists of one ten-coordinate 1:3 Th( $\left.\mathrm{NO}_{3}\right)_{2}$-ligand complex and two outer sphere nitrate anions (Figure 2) with Th-O distances ranging from 2.394 to $2.641 \AA$. The overall metal coordination geometry resembles a distorted bicapped square antiprism where the bidentate nitrate groups occupy the apical positions. Three ligands, all bidentate, are coordinated along the equator of the Th(IV) ion. Two of these coordinated ligands are bound nearly parallel to one another and the equator, while the third is coordinated in a perpendicular orientation (O5 and O6). To accommodate this orientation, the coordination of the apical nitrato groups is tilted slightly away from O5 and O6 of the third ligand.

Extensive pi-pi and $\mathrm{CH}$-pi interactions exist both intramolecularly and intermolecularly throughout the crystal lattice. One phenyl ring (C74-79) is disordered and was modeled with $50 \%$ occupancy over two positions. Both orientations of this disordered ring engage in pistacking interactions with nearby phenyl rings. One outer sphere nitrate was ordered in the matrix, however the second nitrate ion along with, we suspect, solvent methanol or water was disordered in a large space within the crystal lattice (see packing diagram, Figure 3). Attempts to model these disordered molecules were unsuccessful. The intensity contribution of the disordered nitrate and solvent molecules was removed using the BYPASS procedure[27] as implemented in OLEX2.[21, 22] This space is located at average x,y,z coordinates of [-0.537, $0.000,-0.478]$, has a calculated size of $998.5 \AA^{3}$, and contains approximately 170 electrons.
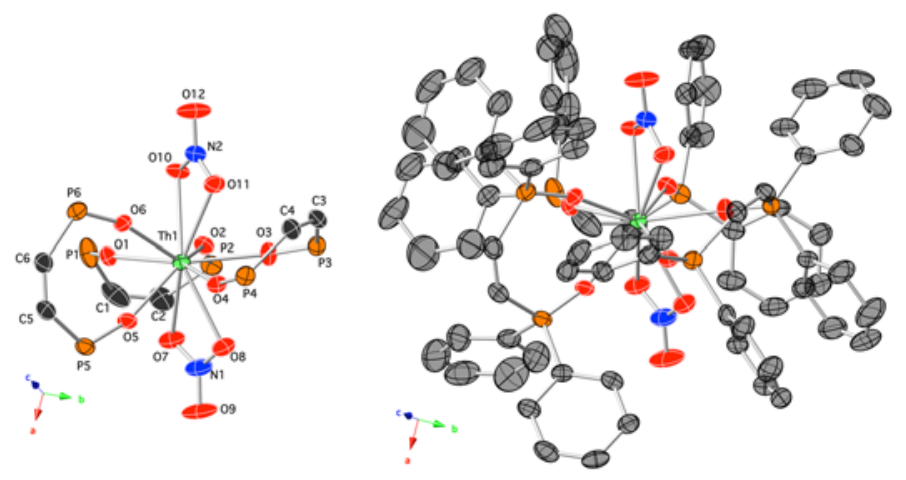

Figure 2. Coordination environment of structure $\mathbf{2}$ with (left) atom numbering scheme and phenyl rings omitted for clarity, and (right) only hydrogens omitted. Only one orientation of the 
disordered phenyl ring C74-79 is shown for clarity; drawings are done at 50\% thermal ellipsoids using standard CPK colors.

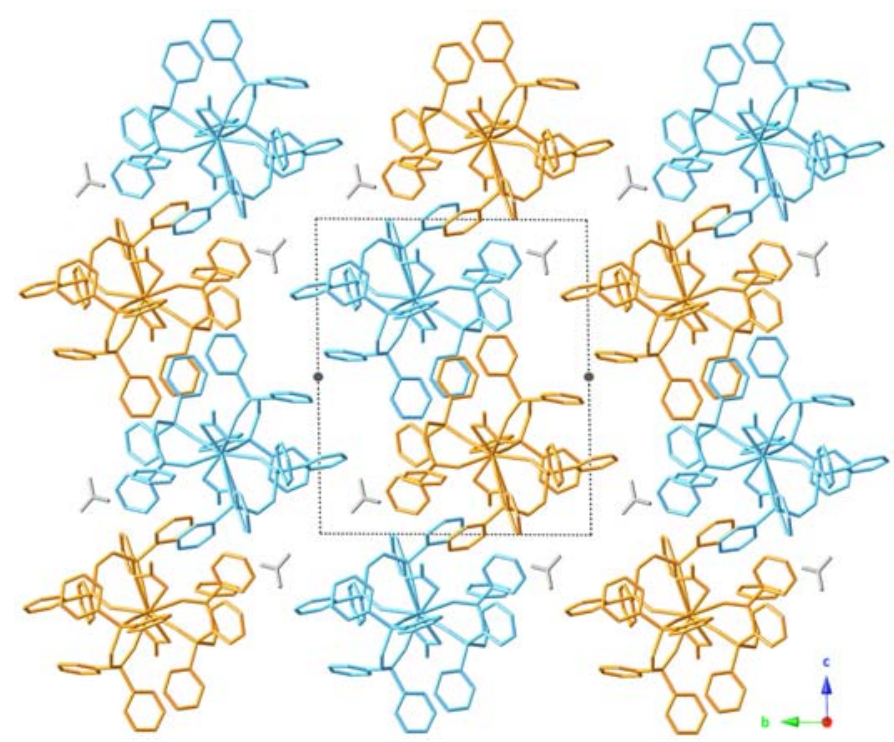

Figure 3. Packing diagram viewed down the $a$-axis showing the ordered outer-sphere nitrate ions (grey sticks) and the spaces in the lattice that hold one disordered nitrate and possibly solvent (denoted with grey dots). Viewed down this axis, pi-pi interactions can be seen between phenyl rings on adjacent metal-ligand complexes (orange and blue sticks). This drawing is done as a stick model; one orientation of the disordered phenyl ring C74-C79 and all hydrogen atoms have been omitted for clarity.

The coordination environment of the Th(IV) metal center in structure $\mathbf{3}$, grown out of the non-coordinating solvent chloroform, is very similar to that of $\mathbf{2}$ grown from methanol (Figure 4). Complex 3 crystallized in the monoclinic space group $P 21 / n$. The asymmetric unit consists of one ten-coordinate 1:3 $\mathrm{Th}\left(\mathrm{NO}_{3}\right)_{2}$-ligand complex, two outer sphere nitrate anions, and one molecule of solvent carbon tetrachloride. This complex, again, is ten-coordinate with a similar arrangement of three ligands and two nitrates bound to the Th(IV) center having Th-O bond distances ranging from 2.3857 to $2.6497 \AA$. Extensive pi-pi stacking interactions can be seen between adjacent molecules of the complex, as shown in Figure 4. One of the aromatic rings, C73-C78, was disordered over two positions (80:20 ratio) where both orientations could participate in favorable $\mathrm{CH}$-pi interactions with neighboring phenyl rings. Due to the close packing of the aromatic groups in this structure, the two orientations of ring C73-C78 affected the position of ring $\mathrm{C} 43-\mathrm{C} 48$ ever so slightly, but enough to merit the modeling of this ring in 
two separate orientations as well. Since this disorder is localized to the pendant aromatic rings and does not affect the metal center, we show both models only in the supporting information.

Two spaces, both having volumes of $1307 \AA^{3}$ and containing approximately 506 electrons, are also present in the unit cell with average $x, y, z$ coordinates of $[-0.019,0.000,0.000]$ and [$0.209,0.500,0.500]$. We suspect these spaces contain a mixture of disordered chloroform and carbon tetrachloride molecules. The intensity contribution of these disordered solvent molecules was removed by the BYPASS procedure[27] as implemented in OLEX2.[21, 22] Pertinent bond lengths and angles for both structures $\mathbf{2}$ and $\mathbf{3}$ are given in Table 2.

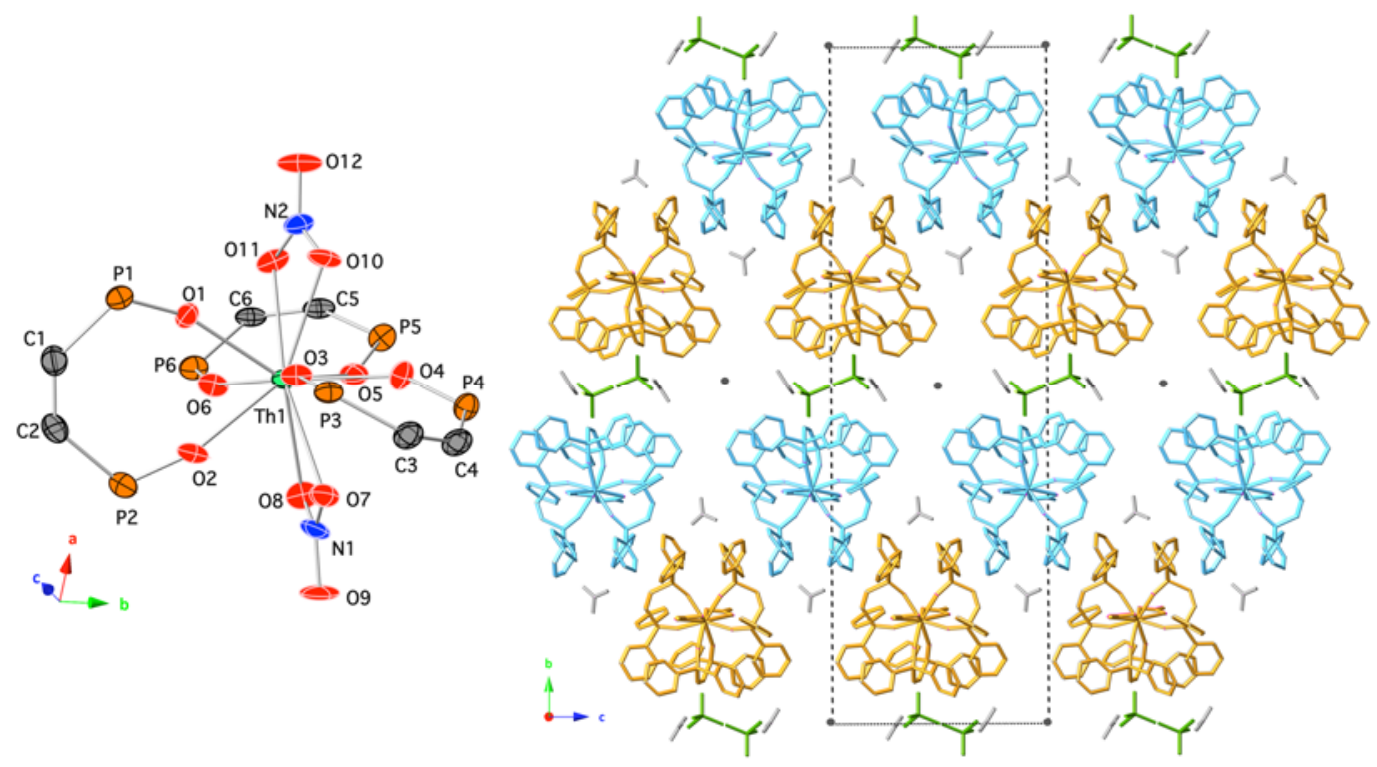

Figure 4. (left) Coordination environment of structure 3 with atom numbering scheme and phenyl rings omitted for clarity. This drawing was done with 50\% thermal ellipsoids using standard CPK colors. (right) Packing diagram of complex 3 viewed down the $a$-axis, only one orientation of the disordered phenyl rings $\mathrm{C} 73-\mathrm{C} 78$ and $\mathrm{C} 43-\mathrm{C} 48$ are shown for clarity. From this viewpoint the ordered outer-sphere $\mathrm{CCl}_{4}$ (light green) and nitrate ions (grey) can be seen, as well as the spaces in the lattice that hold disordered solvent (denoted with a dark grey circle). Intramolecular pi-pi stacking interactions can also be seen. This drawing is done with a stick model; all hydrogen atoms have been omitted for clarity.

Table 2. Crystal and structure refinement data for 2-3.

\begin{tabular}{|l|c|c|}
\hline Data & Structure 2 & Structure 3 \\
\hline Empirical Formula & $\mathrm{C}_{78} \mathrm{H}_{66} \mathrm{~N}_{3} \mathrm{O}_{15} \mathrm{P}_{6} \mathrm{Th}$ & $\mathrm{C}_{79} \mathrm{H}_{66} \mathrm{Cl}_{4} \mathrm{~N}_{4} \mathrm{O}_{18} \mathrm{P}_{6} \mathrm{Th}$ \\
\hline
\end{tabular}




\begin{tabular}{|c|c|c|}
\hline Formula Weight & 1703.19 & 1919.02 \\
\hline Crystal system & triclinic & monoclinic \\
\hline Space group & P-1 & $\mathrm{P} 2_{1} / \mathrm{n}$ \\
\hline CCDC number & 1052114 & 1052127 \\
\hline$a(\AA)$ & $13.0917(14)$ & $11.956(3)$ \\
\hline$b(\AA)$ & $17.0276(18)$ & $51.299(15)$ \\
\hline$c(\AA)$ & $19.920(2)$ & $16.463(5)$ \\
\hline$\alpha\left({ }^{\circ}\right)$ & $87.449(1)$ & 90.00 \\
\hline$\beta\left({ }^{\circ}\right)$ & $79.494(1)$ & $95.647(4)$ \\
\hline$\gamma\left({ }^{\circ}\right)$ & $81.881(1)$ & 90.00 \\
\hline $\mathrm{V}\left(\AA^{3}\right)$ & $4321.5(8)$ & $10048(5)$ \\
\hline $\mathrm{Z}$ & 2 & 4 \\
\hline $\mathrm{D}\left(\mathrm{g} \mathrm{cm}^{-3}\right)$ & 1.309 & 1.268 \\
\hline$\mu\left(\mathrm{mm}^{-1}\right)$ & 1.895 & 1.743 \\
\hline Crystal size $(\mathrm{mm})$ & $0.31 \times 0.262 \times 0.141$ & $0.306 \times 0.169 \times 0.122$ \\
\hline $\begin{array}{l}\text { Minimum/maximum } \\
\text { transmission }\end{array}$ & 0.8757 & 0.7878 \\
\hline$h k l$ ranges & $\begin{array}{l}-15 \leq h \leq 15,-20 \leq \\
k \leq 20,-23 \leq l \leq 24\end{array}$ & $\begin{array}{l}-14 \leq h \leq 14,-61 \leq k \\
\leq 58,-19 \leq l \leq 19\end{array}$ \\
\hline Total reflections & 15815 & 78368 \\
\hline Unique reflections & 13184 & 18058 \\
\hline$R$ (int) & 0.0789 & 0.0793 \\
\hline Parameters & 910 & 770 \\
\hline $\mathrm{R}_{1}^{\mathrm{a}}$ (all data) & 0.0505 & 0.1158 \\
\hline $\mathrm{R}_{1}^{\mathrm{a}}(I>2 \sigma(I))$ & 0.0393 & 0.0890 \\
\hline$w \mathrm{R}_{2}{ }^{\mathrm{b}}$ (all data) & 0.1034 & 0.2025 \\
\hline$w \mathrm{R}_{2}{ }^{\mathrm{b}}(I>2 \sigma(I))$ & 0.0981 & 0.1937 \\
\hline $\begin{array}{l}\text { Max/min residual }\left(\mathrm{e}^{-}\right. \\
\left./ \AA^{3}\right)\end{array}$ & $1.335 /-0.759$ & $2.63 /-2.01$ \\
\hline G.O.F. & 1.044 & 1.093 \\
\hline
\end{tabular}

${ }^{\mathrm{a}} \mathrm{R}_{1}=\Sigma|| \mathrm{F}_{\mathrm{o}}|-| \mathrm{F}_{\mathrm{d}}|/ \Sigma| \mathrm{F}_{\mathrm{o}} \mid$

${ }^{b_{w}} \mathrm{R}_{2}=\left[\Sigma\left[w\left(\mathrm{~F}_{\mathrm{o}}^{2}-\mathrm{F}_{\mathrm{c}}^{2}\right)^{2}\right] / \Sigma\left[w \mathrm{~F}_{\mathrm{o}}^{2}\right]^{2}\right]^{1 / 2}$

Table 3. Selected bond lengths $(\AA)$ and angles $\left({ }^{\circ}\right)$ for structures $\mathbf{2}$ and $\mathbf{3}$.

\begin{tabular}{|l|l|l|l|}
\hline \multicolumn{2}{|c|}{ Structure 2 } & \multicolumn{2}{c|}{ Structure 3 } \\
\hline Th1-O1 & $2.441(3)$ & Th1-O1 & 2.4023 \\
\hline Th1-O2 & $2.444(3)$ & Th1-O2 & 2.4007 \\
\hline
\end{tabular}




\begin{tabular}{|l|l|l|l|}
\hline Th1-O3 & $2.411(3)$ & Th1-O3 & 2.3857 \\
\hline Th1-O4 & $2.425(3)$ & Th1-O4 & 2.4039 \\
\hline Th1-O5 & $2.394(3)$ & Th1-O5 & 2.4214 \\
\hline Th1-O6 & $2.414(3)$ & Th1-O6 & 2.4369 \\
\hline Th1-O7 & $2.633(3)$ & Th1-O7 & 2.6310 \\
\hline Th1-O8 & $2.603(3)$ & Th1-O8 & 2.5659 \\
\hline Th1-O10 & $2.558(3)$ & Th1-O10 & 2.5997 \\
\hline Th1-O11 & $2.641(3)$ & Th1-O11 & 2.6497 \\
\hline O1-Th1-O2 & $70.44(10)$ & O1-Th1-O2 & 69.1 \\
\hline O3-Th1-O4 & $70.66(10)$ & O3-Th1-O4 & 68.5 \\
\hline O5-Th1-O6 & $68.94(10)$ & O5-Th1-O6 & 69.6 \\
\hline O7-Th1-O8 & $48.16(11)$ & O7-Th1-O8 & 49.0 \\
\hline O10-Th1-O11 & $48.69(9)$ & O10-Th1-O11 & 48.3 \\
\hline
\end{tabular}

\subsubsection{Crystal structure of the 1:1 and 1:2 Th-ligand complexes}

To investigate other metal-ligand stoichiometries of the $\mathrm{Th}\left(\mathrm{NO}_{3}\right)_{2}-\mathbf{1}_{3} \cdot\left(\mathrm{NO}_{3}\right)_{2}$ complex, we prepared a concentrated mixture of $\mathrm{Th}\left(\mathrm{NO}_{3}\right)_{4}$ hydrate and ligand $\mathbf{1}$ in methanol with a 1:1 stoichiometric ratio. Upon standing in the refrigerator over three days, plate crystals formed that were suitable for analysis by X-ray diffraction to give structure 4 (Figure 5). This structure was solved in the orthorhombic space group Pbca. Interestingly, both 1:1 and 1:2 Th-ligand complexes were present in the asymmetric unit along with two ordered molecules of solvent methanol. In both Th(IV) complexes, all ligands are bound in a bidentate manner, and all eight nitrate couterions are bound directly to the metal centers. The 1:1 metal-ligand complex is twelve-coordinate and bears five bidentate nitrates, giving this complex an overall -1 charge, while the 1:2 metal-ligand complex is ten-coordinate and bears three bidentate nitrates resulting in an overall +1 charge.

The coordination geometry of the twelve coordinate 1:1 $\left[\mathrm{Th}\left(\mathrm{NO}_{3}\right)_{5}-1\right]^{-1}$ complex resembles an icosahedron. At time of manuscript submission, twelve structures are reported in the Cambridge Structural Database containing a 12-coordinate Th(IV) metal. In eleven of these structures, the 12-coordinate metal is $\mathrm{Th}\left(\mathrm{NO}_{3}\right)_{6}{ }^{2-}$ acting as the anionic counterpart in an ion-pair complex.[28-38] The twelfth includes a Th(IV) metal bearing two bidentate organic ligands and four nitrate ions.[38] Complex 4 described here represents the third structurally unique 
contribution of a 12-coordinate Th(IV) structure to the CSD. Th-O bond distances in this complex range from 2.360 to $2.656 \AA$, slightly longer than the ten-coordinate 1:3 Th-ligand complex described above.

The coordination geometry of the ten-coordinate $1: 2\left[\mathrm{Th}\left(\mathrm{NO}_{3}\right)_{3}-\mathbf{1}\right]^{+1}$ complex again resembles a distorted bicapped square antiprism. The two ligands are bound along the equator of the metal, while two nitrato groups occupy the apical positions. The third nitrato group binds to the metal in the same orientation as the third ligand in complexes $\mathbf{2}$ and $\mathbf{3}$, along the equator but rotated perpendicular to the bound ligands. The apical nitrato groups are tilted slightly away from this third nitrato group, in a similar fashion as seen in complexes $\mathbf{2}$ and $\mathbf{3}$. Th(IV)-O bond distances range from 2.342 to $2.627 \AA$, slightly shorter than that observed in complexes $\mathbf{2}$ and $\mathbf{3}$ above. This decreased bond distance is likely due to the presence of a smaller nitrado group coordinating to the metal center in the place of organic ligand 1. Refinement and crystal structure data for structure 4 is given in Table 4; pertinent bond lengths and angles are listed in Table 5.
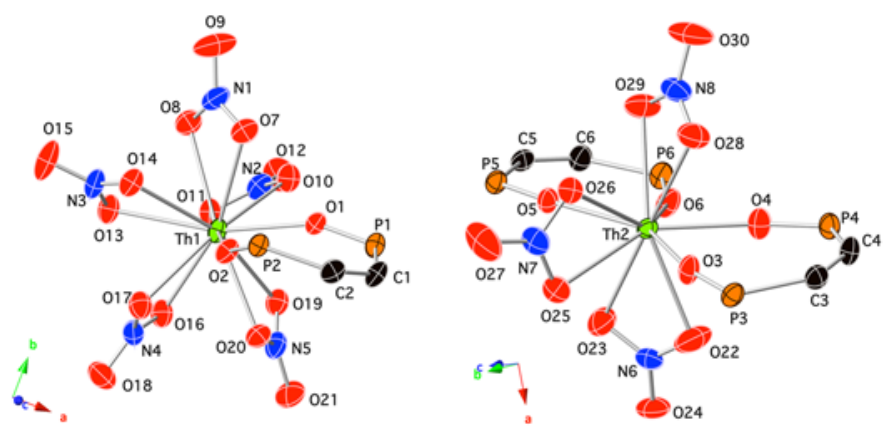

Figure 5. Coordination environment of both Th(IV) atoms in structure 4 with atom numbering scheme and phenyl rings omitted for clarity: (left) Th1 of the 1:1 complex and (right) Th2 of the 1:2 complex. Drawings are done at 50\% thermal ellipsoids using standard CPK colors.

Table 4. Crystal structure and refinement data for 4-5.

\begin{tabular}{|l|l|l|}
\hline Data & \multicolumn{1}{|c|}{ Structure 4 } & \multicolumn{1}{c|}{ Structure 5 } \\
\hline Empirical Formula & $\mathrm{C}_{80} \mathrm{H}_{74} \mathrm{~N}_{8} \mathrm{O}_{32} \mathrm{P}_{6} \mathrm{Th}_{2}$ & $\mathrm{C}_{78} \mathrm{H}_{66} \mathrm{~N}_{2} \mathrm{O}_{13} \mathrm{P}_{6} \mathrm{Th}$ \\
\hline Formula Weight & 2309.37 & 1657.18 \\
\hline Crystal system & orthorhombic & triclinic \\
\hline Space group & Pbca & $\mathrm{P}-1$ \\
\hline CCDC number & 1052128 & 1052129 \\
\hline
\end{tabular}




\begin{tabular}{|c|c|c|}
\hline$a(\AA)$ & $20.4872(3)$ & $12.5057(16)$ \\
\hline$b(\AA)$ & $21.7028(3)$ & $16.069(2)$ \\
\hline$c(\AA)$ & $40.0869(5)$ & $22.475(3)$ \\
\hline$\alpha\left(^{\circ}\right)$ & 90 & $79.639(2)$ \\
\hline$\beta\left({ }^{\circ}\right)$ & 90 & 76.497(2) \\
\hline$\gamma\left({ }^{\circ}\right)$ & 90 & $67.749(2)$ \\
\hline $\mathrm{V}\left(\AA^{3}\right)$ & $17823.8(4)$ & $4043.7(9)$ \\
\hline $\mathrm{Z}$ & 8 & 2 \\
\hline $\mathrm{D}\left(\mathrm{g} \mathrm{cm}^{-3}\right)$ & 1.721 & 1.361 \\
\hline$\mu\left(\mathrm{mm}^{-1}\right)$ & 12.461 & 2.021 \\
\hline Crystal size $(\mathrm{mm})$ & $0.206 \times 0.087 \times 0.084$ & $0.378 \times 0.124 \times 0.046$ \\
\hline $\begin{array}{l}\text { Minimum/maximum } \\
\text { transmission }\end{array}$ & 0.5604 & 0.8288 \\
\hline$h k l$ ranges & $\begin{array}{l}-24 \leq \mathrm{h} \leq 24,-25 \leq \mathrm{k} \leq \\
25,-48 \leq 1 \leq 47\end{array}$ & $\begin{array}{l}-15 \leq \mathrm{h} \leq 15,-19 \leq \mathrm{k} \leq 19, \\
-27 \leq 1 \leq 26\end{array}$ \\
\hline Total reflections & 94226 & 50569 \\
\hline Unique reflections & 16122 & 14955 \\
\hline$R$ (int) & 0.0901 & 0.0656 \\
\hline Parameters & 1157 & 901 \\
\hline $\mathrm{R}_{1}^{\mathrm{a}}$ (all data) & 0.0641 & 0.0585 \\
\hline $\mathrm{R}_{1}^{\mathrm{a}}(I>2 \sigma(I))$ & 0.0445 & 0.0426 \\
\hline$w \mathrm{R}_{2}{ }^{\mathrm{b}}$ (all data) & 0.1126 & 0.0960 \\
\hline$w \mathrm{R}_{2}{ }^{\mathrm{b}}(I>2 \sigma(I))$ & 0.1031 & 0.0910 \\
\hline Max $/$ min residual $\left(\mathrm{e}^{-} / \AA^{3}\right)$ & $3.26 /-1.16$ & $1.72 /-0.96$ \\
\hline G.O.F. & 1.029 & 1.029 \\
\hline
\end{tabular}

${ }^{\mathrm{a}} \mathrm{R}_{1}=\Sigma|| \mathrm{F}_{\mathrm{o}}|-| \mathrm{F}_{\mathrm{d}}|/ \Sigma| \mathrm{F}_{\mathrm{o}} \mid$

${ }^{\mathrm{b}_{w}} \mathrm{R}_{2}=\left[\Sigma\left[w\left(\mathrm{~F}_{\mathrm{o}}{ }^{2}-\mathrm{F}_{\mathrm{c}}\right)^{2}\right] / \Sigma\left[w \mathrm{~F}_{0}^{2}\right]^{2}\right]^{1 / 2}$

Table 5. Selected bond lengths $(\AA)$ and angles $\left({ }^{\circ}\right)$ for structure 4.

\begin{tabular}{|l|l|l|l|}
\hline \multicolumn{2}{|c|}{$1: 1$ Th(IV)-ligand complex } & \multicolumn{2}{c|}{$\mathbf{1 : 2}$ Th(IV)-ligand complex } \\
\hline Th1-O1 & $2.381(5)$ & Th2-O3 & $2.348(5)$ \\
\hline Th1-O2 & $2.360(5)$ & Th2-O4 & $2.342(5)$ \\
\hline Th1-O7 & $2.593(6)$ & Th2-O5 & $2.377(4)$ \\
\hline Th1-O8 & $2.643(5)$ & Th2-O6 & $2.351(5)$ \\
\hline Th1-O10 & $2.601(5)$ & Th2-O22 & $2.557(6)$ \\
\hline Th1-O11 & $2.550(5)$ & Th2-O23 & $2.589(6)$ \\
\hline Th1-O13 & $2.636(5)$ & Th2-O25 & $2.573(5)$ \\
\hline
\end{tabular}




\begin{tabular}{|l|l|l|l|}
\hline Th1-O14 & $2.619(5)$ & Th2-O26 & $2.543(5)$ \\
\hline Th1-O16 & $2.597(5)$ & Th2-O28 & $2.627(5)$ \\
\hline Th1-O17 & $2.607(6)$ & Th2-O29 & $2.550(5)$ \\
\hline Th1-O19 & $2.656(5)$ & O3-Th2-O4 & $73.63(17)$ \\
\hline Th1-O20 & $2.618(5)$ & O5-Th2-O6 & $72.35(17)$ \\
\hline O1-Th1-O2 & $68.23(17)$ & O22-Th2-O23 & $48.31(18)$ \\
\hline O7-Th1-O8 & $48.60(17)$ & O25-Th2-O26 & $50.03(16)$ \\
\hline O10-Th1-O11 & $49.41(16)$ & O28-Th2-O29 & $48.80(18)$ \\
\hline O13-Th1-O14 & $48.44(15)$ & & \\
\hline O16-Th1-O17 & $48.85(16)$ & & \\
\hline O19-Th1-O20 & $47.98(16)$ & & \\
\hline
\end{tabular}

\subsubsection{Serendipitous crystal structure of the 1:3 Th-ligand complex with an epoxide}

The fourth structure we describe here was a serendipitous discovery from our investigations into the $\mathrm{Th}\left(\mathrm{NO}_{3}\right)_{2}-\mathbf{1}_{3} \cdot\left(\mathrm{NO}_{3}\right)_{2}$ complex. This structure was obtained from a concentrated solution of the $\mathrm{Th}\left(\mathrm{NO}_{3}\right)_{2}-\mathbf{1}_{3} \cdot\left(\mathrm{NO}_{3}\right)_{2}$ dissolved in methanol, but crystallized with vapor diffusion of diisopropylether. In this case, structure 5 crystallized in the triclinic space group P-1 as a 1:3 metal-ligand complex with one ligand bearing an epoxide in place of the alkene (Figure 6, structure and refinement details in Table 4). The asymmetric unit contains one ten-coordinate Th(IV) center bearing three ligands and two nitrato groups, each bound in a bidentate manner.

The two outer sphere nitrates were severely disordered in the crystal lattice, perhaps along with solvent molecules, and their electron density contribution was removed using the BYPASS[27] procedure in Olex2.[21, 22] Two spaces were found per unit cell with average xyz coordinates of $[-0.500,0.500,0.000]$ and $[-0.646,0.500,0.500]$ containing approximately 99 and 148 electrons, respectively. The packing diagram in Figure 6 shows the large, oval-shaped space located in the center of the unit cell containing this disordered electron density. The phenyl rings of the ligands creating the border of this oval-shaped space have relatively large thermal values, likely because there are no ordered hydrocarbon structures with which to engage in pi-pi or $\mathrm{CH}$ pi interactions. The phenyl rings on the opposite side of the complex engage in extensive intermolecular pi-pi stacking interactions with nearby complexes. These relatively ordered rings can also be seen in Figure 6 denoted by a grey arrow. The range of Th-O bond lengths was 2.377(3)-2.642(3) Å; selected bond lengths and angles are given in Table 6.

The overall geometry of this ten-coordinate complex again resembles a distorted bicapped 
square antiprism. The inner sphere nitrato groups occupy the apical positions, and the three organic ligands are bound along the equator of the complex. A subtle difference is seen here, however, when compared to the parent 1:3 Th(IV)-ligand structure 2. The ligand bearing the epoxide is bound with both oxygen atoms approximately perpendicular to the apical nitrates. This orientation is likely stabilized by favorable electrostatic interactions between the epoxide oxygen $\mathrm{O} 13$ and the bound nitrato nitrogen N2 (interatomic distance $=2.811 \AA$ ). The other two bound ligands are both tilted slightly toward the apical positions, rather than one parallel to and one perpendicular to the first ligand (as seen in structures $\mathbf{2}$ and $\mathbf{3}$ ).

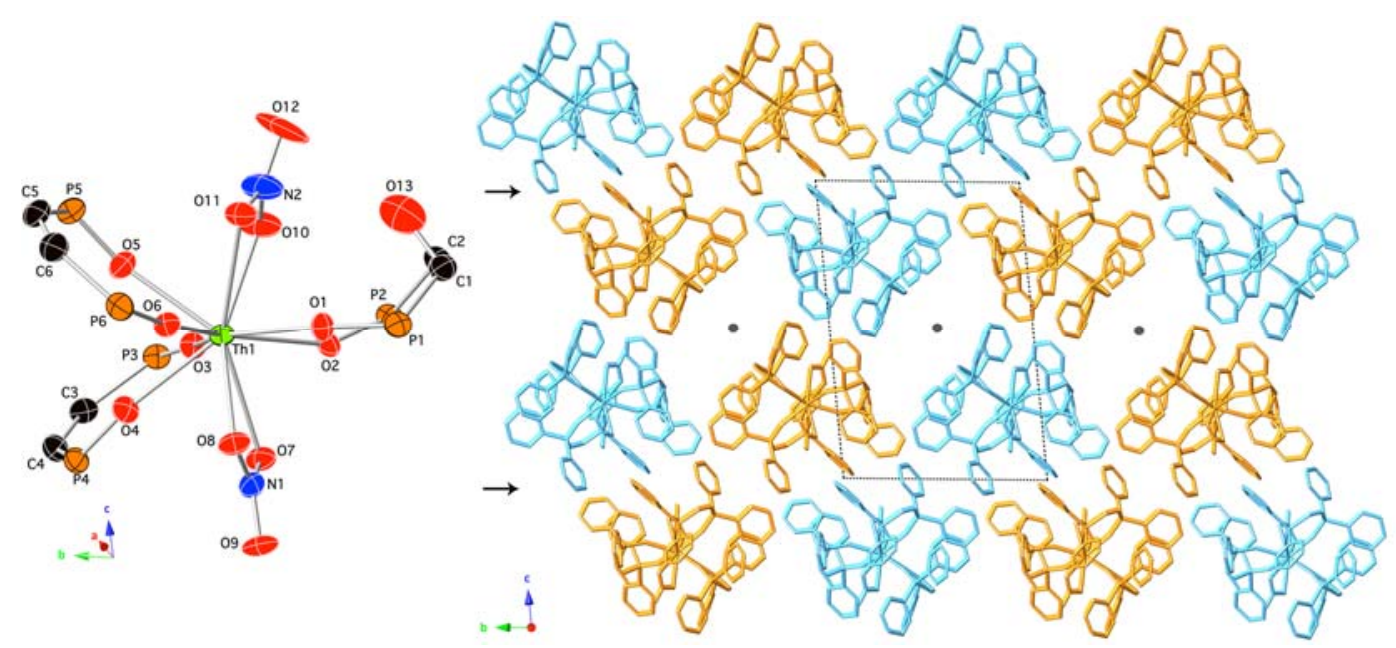

Figure 6. (left) Coordination environment of Th(IV) in structure 5 with atom numbering scheme and phenyl rings omitted for clarity. This drawing was done with 50\% thermal ellipsoids using standard CPK colors. (right) Packing diagram of complex 5 viewed down the $a$-axis. From this viewpoint the large spaces in the center of the unit cell, denoted with a grey circle, can be seen that likely hold disordered nitrate ions and possibly solvent. Black arrows indicate pi-stacking interactions between adjacent complexes. This drawing is done as a stick model and each complex is colored completely in either blue or orange, with hydrogen atoms omitted, for clarity.

Table 6. Selected bond lengths $(\AA)$ and angles $\left(^{\circ}\right)$ for structure 5.

\begin{tabular}{|l|l|}
\hline Th1-O1 & $2.435(3)$ \\
\hline Th1-O2 & $2.489(3)$ \\
\hline Th1-O3 & $2.377(3)$ \\
\hline Th1-O4 & $2.411(3)$ \\
\hline Th1-O5 & $2.413(3)$ \\
\hline
\end{tabular}




\begin{tabular}{|l|l|}
\hline Th1-O6 & $2.403(3)$ \\
\hline Th1-O7 & $2.616(3)$ \\
\hline Th1-O8 & $2.585(3)$ \\
\hline Th1-O10 & $2.543(3)$ \\
\hline Th1-O11 & $2.642(3)$ \\
\hline C1-O13 & $1.4334(7)$ \\
\hline C2-O13 & $1.439(6)$ \\
\hline O1-Th1-O2 & $68.86(10)$ \\
\hline O3-Th1-O4 & $69.31(10)$ \\
\hline O5-Th1-O6 & $71.11(11)$ \\
\hline O7-Th1-O8 & $48.83(10)$ \\
\hline O10-Th1-O11 & $48.95(11)$ \\
\hline C1-O13-C2 & $60.9(4)$ \\
\hline
\end{tabular}

As for the formation of the 1:3 Th-ligand complex bearing an epoxide in solution, we have a few hypotheses. Our first thought was that the metal bound ligand bearing an epoxide was a small impurity from the preparation of ligand $\mathbf{1}$, and perhaps due to the extra electrostatic interaction between the epoxide and metal bound nitrato group this 1:3 metal-ligand species crystallizes out of solution selectively. However, we see no indication of this putative ligand impurity in the ${ }^{31} \mathrm{P}$ NMR or CHN analysis of the free ligand.

We then turned our thoughts to the reported reactive ability of Th(IV) toward activated alkenes. There have been two reports in the literature of Th(IV) acting as a catalyst in the epoxidation of activated alkenes in the presence of tBuOOH.[39, 40] There are two possible sources of peroxide contamination in our crystallization experiments. Hypothesis 1: Our ligand was prepared using hydrogen peroxide as the phosphine oxidant, and although the product was recrystallized from benzene it could be possible that trace amounts of hydrogen peroxide were present in this batch of ligand. However, we see no signals corresponding to $\mathrm{HOOH}$ in the ${ }^{1} \mathrm{H}$ NMR of our ligand, and the CHN analysis further attests to the purity ( $\geq 95 \%$ ) of our product. Hypothesis 2: The solvent used to crystallize this complex via vapor diffusion was diisopropyl ether, which could have trace amounts of peroxides present in solution. As a result of this crystal structure we tested our bottle of $\mathrm{irO}_{2}$ with peroxide test strips and did not detect the presence of peroxides in our solvent (detection limit is approximately $0.5 \mathrm{ppm}$ or $1 \mathrm{mg}$ peroxide/liter of solvent). We also note here that we have not observed this epoxide-containing structure under any other conditions than with the $\operatorname{Pr}_{2} \mathrm{O}$ vapor diffusion into a methanolic solution of $1: 3$ metal- 
ligand complex. At this point, we have no conclusive evidence for an explanation for the generation of this epoxide-containing structure.

\subsubsection{Experiments to reproduce the 1:3 complex bearing an epoxide: three more crystal structures}

In attempt to reproduce the epoxide structure, we prepared a new methanolic solution of $\mathrm{Th}\left(\mathrm{NO}_{3}\right)_{2}-\mathbf{1}_{3} \cdot\left(\mathrm{NO}_{3}\right)_{2}$ complex and set up three crystallization experiments with varying equivalents $(1,2$ and 3$)$ of $\mathrm{tBuOOH}$. Our rationale here was to try increase the amount of epoxidation occurring in solution (if, in fact, Th(IV) or peroxide catalysis is involved) and isolate more crystals to study. The metal-ligand-peroxide solutions were allowed to stir for one hour at room temperature, and crystallization was induced with vapor diffusion of both benzene and ${ }_{i \operatorname{Pr}} \mathrm{O}$ (separate experiments) at $4{ }^{\circ} \mathrm{C}$. From the crystals that formed in these experiments we did not observe a complex bearing an epoxide on one or more bound ligands. We did, however, crystallize two new polymorphs 6 and 7 of the 1:3 Th(IV)-ligand complex varying only in the amount and location of solvent in the crystal lattice. Structure and refinement data for structures 6 and 7 are given in Table 7, while pertinent bond lengths and angles for these new structures can be found in Table 8. Th(IV)-O bond lengths range from 2.413(4) to 2.700(4) $\AA$ for structure 6, and 2.391(3) to $2.663 \AA$ for structure 7.

Table 7. Crystal structure and refinement data for 6-8.

\begin{tabular}{|l|l|l|l|}
\hline Data & \multicolumn{1}{|c|}{ Structure 6 } & \multicolumn{1}{c|}{ Structure 7 } & \multicolumn{1}{c|}{ Structure 8 } \\
\hline Empirical Formula & $\mathrm{C}_{81} \mathrm{H}_{80} \mathrm{~N}_{3} \mathrm{O}_{19} \mathrm{P}_{6} \mathrm{Th}$ & $\mathrm{C}_{80} \mathrm{H}_{74} \mathrm{~N}_{3} \mathrm{O}_{17} \mathrm{P}_{6} \mathrm{Th}$ & $\mathrm{C}_{156} \mathrm{H}_{138} \mathrm{~N}_{7} \mathrm{O}_{36} \mathrm{P}_{12} \mathrm{Th}_{2}$ \\
\hline Formula Weight & 1817.34 & 1767.28 & 3522.45 \\
\hline Crystal system & triclinic & triclinic & triclinic \\
\hline Space group & $\mathrm{P}-1$ & $\mathrm{P}-1$ & $\mathrm{P}-1$ \\
\hline CCDC number & 1052130 & 1052131 & 1052132 \\
\hline$a(\AA)$ & $13.3259(17)$ & $13.4174(15)$ & $13.2034(14)$ \\
\hline$b(\AA)$ & $15.634(2)$ & $15.7703(18)$ & $23.440(3)$ \\
\hline$c(\AA)$ & $20.525(3)$ & $20.555(2)$ & $26.574(3)$ \\
\hline$\alpha\left({ }^{\circ}\right)$ & $84.769(2)$ & $86.993(1)$ & $74.120(1)$ \\
\hline$\beta\left(^{\circ}\right)$ & $79.961(1)$ & $81.113(1)$ & $81.997(1)$ \\
\hline$\gamma\left({ }^{\circ}\right)$ & $81.617(2)$ & $84.995(1)$ & $78.611(1)$ \\
\hline $\mathrm{V}\left(\AA^{3}\right)$ & $4156.2(9)$ & $4277.4(8)$ & $7723.0(14)$ \\
\hline
\end{tabular}




\begin{tabular}{|c|c|c|c|}
\hline $\mathrm{Z}$ & 2 & 2 & 2 \\
\hline $\mathrm{D}\left(\mathrm{g} \mathrm{cm}^{-3}\right)$ & 1.452 & 1.372 & 1.515 \\
\hline$\mu\left(\mathrm{mm}^{-1}\right)$ & 1.979 & 1.919 & 2.126 \\
\hline Crystal size (mm) & $0.378 \times 0.18 \times 0.09$ & $0.355 \times 0.317 \times 0.142$ & $0.265 \times 0.213 \times 0.064$ \\
\hline $\begin{array}{l}\text { Minimum/maximum } \\
\text { transmission }\end{array}$ & 0.8359 & 0.8197 & 0.7562 \\
\hline$h k l$ ranges & $\begin{array}{l}-16 \leq \mathrm{h} \leq 16,-18 \leq \mathrm{k} \\
\leq 18,-24 \leq 1 \leq 24\end{array}$ & $\begin{array}{l}-16 \leq \mathrm{h} \leq 16,-19 \leq \mathrm{k} \leq \\
19,-25 \leq 1 \leq 25\end{array}$ & $\begin{array}{l}-14 \leq \mathrm{h} \leq 16,-28 \leq \mathrm{k} \leq \\
28,-32 \leq 1 \leq 32\end{array}$ \\
\hline Total reflections & 50948 & 73664 & 84779 \\
\hline Unique reflections & 15279 & 16976 & 30169 \\
\hline$R$ (int) & 0.0446 & 0.0499 & 0.0671 \\
\hline Parameters & 988 & 968 & 1925 \\
\hline $\mathrm{R}_{1}^{\mathrm{a}}$ (all data) & 0.0549 & 0.0601 & 0.0971 \\
\hline $\mathrm{R}_{1}^{\mathrm{a}}(I>2 \sigma(I))$ & 0.0443 & 0.0463 & 0.0599 \\
\hline$w \mathrm{R}_{2}{ }^{\mathrm{b}}$ (all data) & 0.1146 & 0.1081 & 0.1269 \\
\hline$w \mathrm{R}_{2}{ }^{\mathrm{b}}(I>2 \sigma(I))$ & 0.1103 & 0.1032 & 0.1187 \\
\hline $\begin{array}{l}\text { Max/min residual } \\
\left(\mathrm{e}^{-} / \AA^{3}\right)\end{array}$ & $5.60 /-1.18$ & $2.60 /-1.18$ & $2.06 /-3.42$ \\
\hline G.O.F. & 1.074 & 1.044 & 1.097 \\
\hline
\end{tabular}

${ }^{\mathrm{a}} \mathrm{R}_{1}=\Sigma|| \mathrm{F}_{\mathrm{o}}|-| \mathrm{F}_{\mathrm{d}}|/ \Sigma| \mathrm{F}_{\mathrm{o}} \mid$

${ }^{\mathrm{b}} w \mathrm{R}_{2}=\left[\Sigma\left[w\left(\mathrm{~F}_{\mathrm{o}}{ }^{2}-\mathrm{F}_{\mathrm{c}}\right)^{2}\right] / \Sigma\left[w \mathrm{~F}_{\mathrm{o}}{ }^{2}\right]^{2}\right]^{1 / 2}$

The coordination geometry of the metal center in both structures $\mathbf{6}$ and $\mathbf{7}$ is very similar to structure 2 described above, so we have included drawings of these complexes only in the supplemental information. Packing diagrams of these structures showing their different morphologies are shown in Figure 7. Both structures $\mathbf{6}$ and $\mathbf{7}$ bear three bidentate ligands and two bidentate nitrato groups, and were solved in the triclinic space group P-1. These new structures have similar unit cell dimensions to structure 2 , however the unit cell volumes vary slightly from $4321.1 \AA^{3}$ for structure $\mathbf{2}$, to 4156.2 and $4277.4 \AA^{3}$ for 6 and 7, respectively. Structure 6 boasts one ordered outer sphere nitrate ion, three methanol molecules and one water. The remaining outer sphere nitrate ion, likely along with additional solvent, was severely disordered. The electron contribution to this disorder, in a space of $300.7 \AA^{3}$ containing 82 electrons, was removed using the BYPASS procedure[27] as implemented in OLEX2.[21, 22] This space has average xyz coordinates of $[-0.500,0.000,0.500]$. Structure 7 has one ordered outer sphere nitrate and two methanol molecules. The remaining nitrate ion, likely along with additional 
solvent, was disordered in the lattice. The electron contribution to this disorder, in a space of $670.3 \AA^{3}$ located at average xyz coordinates of [-0.332, 0.500, 0.500], was also removed using the BYPASS procedure. This space was calculated to contain approximately 138 electrons.



Figure 7. Packing diagrams of structures 6 and 7. (a, left) Complex 6 and (b, right) complex 7, both viewed down the $a$-axis. Spaces containing disordered electron density are denoted with a grey circle; unbound nitrate ions as well as solvent water and methanol molecules are shown as light grey sticks. This drawing is done as a stick model; all hydrogen atoms have been omitted for clarity.

Table 8. Selected bond lengths $(\AA)$ and angles $\left({ }^{\circ}\right)$ for structures 6 and 7.

\begin{tabular}{|l|l|l|l|}
\hline \multicolumn{2}{|c|}{ Structure 6 } & \multicolumn{2}{c|}{ Structure 7 } \\
\hline Th1-O1 & $2.406(3)$ & Th1-O1 & $2.401(3)$ \\
\hline Th1-O2 & $2.413(4)$ & Th1-O2 & $2.391(3)$ \\
\hline Th1-O3 & $2.424(3)$ & Th1-O3 & $2.440(4)$ \\
\hline Th1-O4 & $2.443(4)$ & Th1-O4 & $2.437(3)$ \\
\hline Th1-O5 & $2.402(3)$ & Th1-O5 & $2.407(4)$ \\
\hline Th1-O6 & $2.404(3)$ & Th1-O6 & $2.429(3)$ \\
\hline Th1-O7 & $2.700(4)$ & Th1-O7 & $2.663(3)$ \\
\hline Th1-O8 & $2.567(3)$ & Th1-O8 & $2.562(3)$ \\
\hline Th1-O10 & $2.593(4)$ & Th1-O10 & $2.609(4)$ \\
\hline Th1-O11 & $2.638(4)$ & Th1-O11 & $2.619(4)$ \\
\hline O1-Th1-O2 & $70.06(12)$ & O1-Th1-O2 & $69.96(11)$ \\
\hline O3-Th1-O4 & $69.99(12)$ & O3-Th1-O4 & $69.89(12)$ \\
\hline
\end{tabular}




\begin{tabular}{|l|l|l|l|}
\hline O5-Th1-O6 & $69.48(11)$ & O5-Th1-O6 & $70.95(11)$ \\
\hline O7-Th1-O8 & $47.96(11)$ & O7-Th1-O8 & $48.40(10)$ \\
\hline O10-Th1-O11 & $48.21(12)$ & O10-Th1-O11 & $48.68(14)$ \\
\hline
\end{tabular}

As part of these experiments a crystal was also isolated with two different Th(IV)-ligand complexes in the asymmetric unit (structure 8, Figure 8). This structure was solved in the triclinic space group P-1. In the first complex, Th1 bears two bidentate nitrato groups, two bidentate ligands, one monodentate ligand and one water molecule. The second complex, Th2, has a 1:3 metal-ligand ratio and is similar in coordination geometry to the parent structure 2 . The two Th(IV) complexes are packed tightly within the asymmetric unit; multiple intermolecular $\mathrm{CH}-$ pi interactions are seen between ligands on neighboring complexes. As a likely consequence of this tight packing, three nitrates and two waters were found ordered in the crystal lattice. The remaining nitrate and likely solvent was disordered and all attempts to model this disorder were unsuccessful. The electron density contribution to this disorder was removed using the BYPASS procedure to give a space of $439.9 \AA^{3}$ located at average xyz coordinates of $[-0.651,0.000,0.500]$ containing approximately 104 electrons. Crystal structure and refinement data for $\mathbf{8}$ is given in Table 7.

The coordination geometry of metal center Th1 is shown in Figure 8. The water molecule has displaced one of the oxygens from the ligand oriented perpendicular to the equator, and the complex retains the distorted antiprism geometry around the ten-coordinate $\mathrm{Th}(\mathrm{IV})$. The water molecule is engaged in hydrogen bonds with one bound nitrato group, one unbound nitrate, and the mondentate ligand. The bond angle between this water oxygen and the monodentate ligand oxygen (O19 and $\mathrm{O} 1)$ at $70.18(15)^{\circ}$ is the same, within error, to the bond angle of the bound bidentate ligand of the other Th(IV) complex in this asymmetric unit (O11 and O12) at $69.95(15)^{\circ}$. Analysis of the packing diagram of structure $\mathbf{8}$ viewed down the $a$-axis reveals the oval shaped space occupied by disordered nitrates and likely solvent molecules (Figure 9). This space is lined with non-polar aromatic rings of the ligands, resulting in a hydrophobic cavity occupied by polar molecules. Pertinent bond lengths and angles for both Th-ligand complexes of structure $\mathbf{8}$ are given in Table 9. 


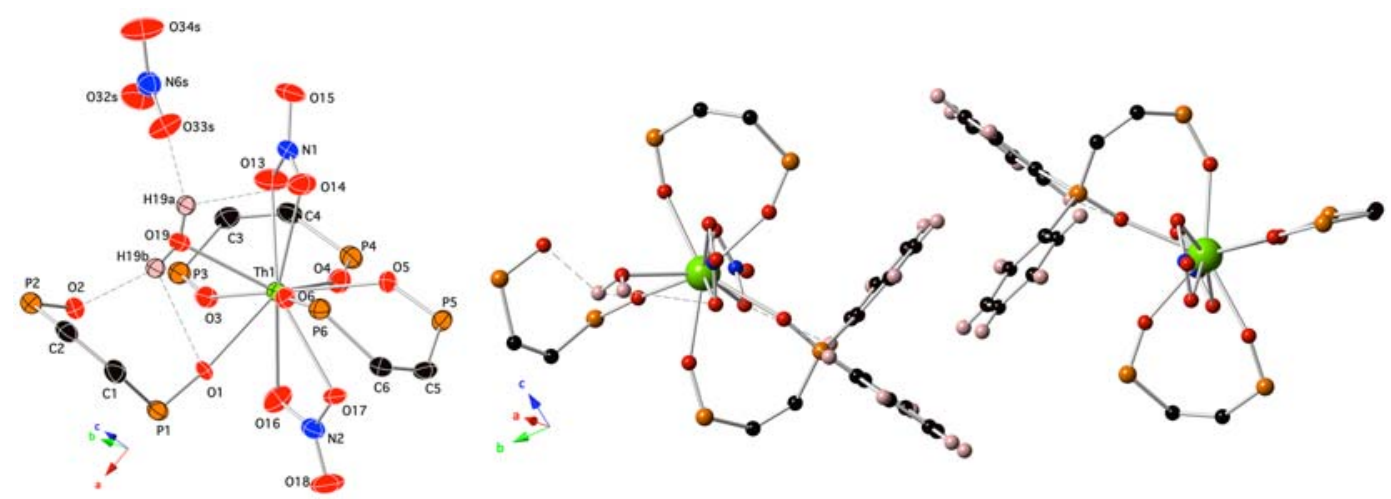

Figure 8. (left) Coordination environment of Th1 in structure 8 with atom numbering scheme and phenyl rings omitted for clarity; hydrogen bonds are shown as dashed grey lines and atoms are depicted as 50\% thermal ellipsoids. (right) Coordination environments of both $\mathrm{Th} 1$ and $\mathrm{Th} 2$ within the asymmetric unit viewed down the apical nitrates; four phenyl rings involved in $\mathrm{CH}$-pi interactions are shown with ball and stick drawings. Only hydrogen atoms involved in hydrogen bonding or CH-pi interactions are shown (light pink); standard CPK colors are used for the rest of the atoms.



Figure 9. Packing diagram of complex 8 viewed down the $a$-axis. From this viewpoint the spaces holding disordered nitrate ions and possibly solvent can be seen and are denoted with a grey circle. This drawing is done as a stick model where the blue complexes contain Th1 and the orange complexes contain Th2. Outer sphere nitrate ions and water molecules are shown as light 
grey sticks, and all hydrogen atoms have been omitted for clarity.

Table 9. Selected bond lengths $(\AA)$ and angles $\left({ }^{\circ}\right)$ for both Th(IV) complexes of structure 8 .

\begin{tabular}{|l|l|l|l|}
\hline \multicolumn{2}{|c|}{$8($ Th1 $)$} & \multicolumn{2}{c|}{$8($ Th2 $)$} \\
\hline Th1-O1 & $2.428(4)$ & Th2-O7 & $2.446(5)$ \\
\hline Th1-O3 & $2.423(5)$ & Th2-O8 & $2.397(5)$ \\
\hline Th1-O4 & $2.393(5)$ & Th2-O9 & $2.420(5)$ \\
\hline Th1-O5 & $2.484(4)$ & Th2-O10 & $2.413(5)$ \\
\hline Th1-O6 & $2.401(5)$ & Th2-O11 & $2.433(4)$ \\
\hline Th1-O13 & $2.606(5)$ & Th2-O12 & $2.386(5)$ \\
\hline Th1-O14 & $2.542(5)$ & Th2-O20 & $2.573(5)$ \\
\hline Th1-O16 & $2.707(5)$ & Th2-O21 & $2.678(5)$ \\
\hline Th1-O17 & $2.561(4)$ & Th2-O23 & $2.653(5)$ \\
\hline Th1-O19 & $2.422(4)$ & Th2-O24 & $2.589(5)$ \\
\hline O1-Th1-O19 & $70.18(15)$ & O7-Th2-O8 & $70.85(16)$ \\
\hline O3-Th1-O4 & $72.60(16)$ & O9-Th2-O10 & $70.25(17)$ \\
\hline O5-Th1-O6 & $69.21(15)$ & O11-Th2-O12 & $69.65(15)$ \\
\hline O13-Th1-O14 & $48.97(17)$ & O20-Th2-O21 & $48.66(15)$ \\
\hline O16-Th1-O17 & $47.95(15)$ & O23-Th2-O24 & $48.45(16)$ \\
\hline
\end{tabular}

\section{Scope and outlook}

This report of seven new crystal structures adds to the current body of Th(IV) coordination complexes within the CSD. The range of structures solved here offers a series of "snapshots" of the dynamic behavior of this Th-ligand complex in solution. These different structures are also observable as a mixture in solution depending on the choice of solvent. We note here that the exceptional crystalline nature of this Th-ligand complex is due, we propose, to the rigid nature of the organic ligand. Extensive intramolecular pi-pi and $\mathrm{CH}-$ pi interactions between pendant aromatic rings on adjacent complexes likely strengthen and solidify the crystal lattice. This is a useful strategy to consider in the design of new ligands as chelators for Th(IV) and other $f$ elements where the coordination geometry of the complex is often dominated by the ligand. 


\section{Acknowledgements}

We thank Grand Valley State University (Weldon Fund, OURS, CSCE) for financial support of this work. We are grateful to the NSF for student support (REU-1062944) and NMR instrumentation (300 MHz JEOL, CCLI-0087655), as well as Pfizer, Inc. for the generous donation of a Varian Inova 400 FT NMR. The CCD based X-ray diffractometers at Michigan State University were upgraded and/or replaced by departmental funds. We also thank Prof. Pablo Ballester (ICIQ) for fruitful conversations, and Prof. James Krikke and Prof. William Winchester (GVSU) for help with instrumentation at GVSU.

\section{Literature Cited}

1. McKetta, J. J. Encyclopedia of Chemical Processing and Design. 1997.

2. Marks, T. J.; Streitwiser, J. A. The Chemistry of the Actinide Elements. Chapman and Hall: London, 1986; Vol. 2.

3. Tsoulfanidis, N. The Nuclear Fuel Cycle. American Nuclear Society: La Grange Park, 2013; p 478.

4. Andrea, T.; Eisen, M. S., "Recent advances in organothorium and organouranium catalysis". Chem. Soc. Rev. 2008, 37, 550-567.

5. Travia, N. E.; Scott, B. L.; Kiplinger, J. L., "A rare tetranuclear thorium(IV) $\mu$ 4-oxo cluster and dinuclear thorium(IV) complex assembled by carbon-oxygen bond activation of 1,2dimethoxyethane (DME)". Chem. Eur. J. 2014, 20, 16846-16852.

6. Siladke, N. A.; Webster, C. L.; Walensky, J. R.; Takase, M. K.; Ziller, J. W.; Grant, D. J.; Gagliardi, L.; Evans, W. J., "Actinide metallocene hydride chemistry: C-H activation in tetramethylcyclopentadienyl ligands to form [ $\mu-\eta 5-\mathrm{C} 5 \mathrm{Me} 3 \mathrm{H}(\mathrm{CH} 2)-\mathrm{kC}] 2$-tuck over ligands in a tetrathorium octahydride complex". Organometallics 2013, 32, 6522-6531.

7. Dash, A. K.; Wang, J. Q.; Eisen, M. S., "Catalytic Hydrosilylation of Terminal Alkynes Promoted by Organoactinides". Organometallics 1999, 18, 4724-4741.

8. Stubbert, B. D.; Marks, T. J., "Constrained geometry organoactinides as versatile catalysts for the intramolecular hydroamination/cyclization of primary and secondary amines having diverse tethered C-C unsaturation". J. Am. Chem. Soc. 2007, 129, 4253-4271.

9. Haksel, A.; Straub, T.; Eisen, M. S., "Organoactinide-Catalyzed Intermolecular Hydroamination of Terminal Alkynes". Organometallics 1996, 15, 3773-3775. 
10. Straub, T.; Frank, W.; Reiss, G. J.; Eisen, M. S., "Uranium(IV) bis(amido), imido and bis(acetylide) complexes: synthesis, molecular structure, solution dynamics and interconversion reactions". J. Chem. Soc. Dalton Trans. 1996, 2541-2546.

11. Sharma, M.; Andrea, T.; Brookes, N. J.; Yates, B. F.; Eisen, M. S., "Organoactinides promote the dimerization of aldehydes: Scope, kinetics, thermodynamics and calculation studies". J. Am. Chem. Soc. 2011, 133, 1341-1356.

12. Moss, R. A.; Morales-Rojas, H.; Vijayaraghavan, S.; Tian, J., "Metal-cation-mediated hydrolysis of phosphonoformate diesters: Chemoselectivity and catalysis". J. Am. Chem. Soc. 2004, 126, 10923-10936.

13. Allen, F. R., "The Cambridge Structural Database: a quarter of a million crystal structures and rising". Acta Cryst. 2002, B58, 380-388.

14. Aguiar, A. M.; Daigle, D. J., "A stereospecific route to trans- and cis-1.2vinylenebis(diphenylphosphine)". J. Am. Chem. Soc. 1964, 86, 2299-2300.

15. Duncan, M.; Gallagher, M. J., "The ${ }^{1} \mathrm{H},{ }^{13} \mathrm{C}$ and ${ }^{31} \mathrm{P}$ NMR spectra of $E Z$ pairs of some phosphorus substituted alkenes". Org. Magn. Res. 1981, 15, 37-42.

16. COSMO v1.61 Software for the CCD detector systems for determining data collection parameters, Bruker Analytical X-ray Systems: Madison, WI, 2009.

17. APEX2 v2010.11-3 Software for the CCD detector system, Bruker Analytical X-ray Systems: Madison, WI, 2010.

18. SAINT v7.68A Software for the Integration of CCD Detector System, Bruker Analytical Xray Systems: Madison, WI, 2010.

19. Blessing, R. H., "SADABS v2.008/2 Program for absorption correction using Bruker-AXS CCD based on the method of Robert Blessing". Acta Cryst. 1995, A51, 33-38.

20. Sheldrick, G. M., "A short history of SHELX". Acta Cryst. 2008, A64, 112-122.

21. Dolomanov, O. V.; Bourhis, L. J.; Gildea, R. J.; Howard, J. A. K.; Puschmann, H., "OLEX2: a complete structure solution, refinement and analysis program". J. Appl. Cryst. 2009, 42, 339-341.

22. Dolomanov, O. V.; Gildea, R. J.; Howard, J. A. K.; Puschmann, H.; Bourhis, L. J., "The anatomy of a comprehensive constrained, restrained, refinement program for the modern computing environment - Olex2 dissected". Acta Cryst. 2015, A71, 59-75.

23. Caddy, J.; Coyanis, E. M.; Fernandes, M. A.; Khanye, S. D.; Omondi, B., "cisEthylenebis(diphenylphosphine oxide)". Acta Cryst. 2007, E63, o1387-o1389. 
24. Carnall, W. T.; Siegel, S.; Ferraro, J. R.; Tani, B.; Gebert, E., "New series of anhydrous double nitrate salts of the lanthanides. Structural and spectral characterization". Inorg. Chem. 1973, 12, 560-564.

25. Kumar, D. S.; Alexander, V., "Macrocyclic complexes of lanthanides in identical ligand frameworks part 1. Synthesis of lanthanide(III) and yttrium(III) complexes of an 18membered dioxatetraaza macrocycle". Inorg. Chim. Acta. 1995, 238, 63-71.

26. Aruna, V. A. J.; Alexander, V., "Synthesis of lanthanide(III) complexes of a 20-membered hexaaza macrocycle". J. Chem. Soc., Dalton Trans. 1996, 1867-1873.

27. van der Sluis, P.; Spek, A. L., "BYPASS: an effective method for the refinement of crystal structures containing disordered solvent regions". Acta Cryst. 1990, A46, 194-201.

28. Abram, U.; Bonfada, É.; Schulz-Lang, E., "Bis \{2-[1-(thiosemicarbazono)ethyl]-pyridinium\} hexakis(nitrato-O,O')-thorate(IV) tetramethanol solvate". Acta Cryst. 1999, C55, 1479-1482.

29. Ming, W.; Boyi, W.; Peiju, Z.; Wenji, W.; Jie, L., "Structure of the extraction complex bis[(dicyclohexano-18-crown-6)oxonium] Hexanitratothorate(IV) isomer A". Acta Cryst 1988, C44, 1913-1916.

30. Apama, K.; Krishnamurthy, S. S.; Nethaji, M., "Synthetic, spectroscopic and structural studies on uranium and thorium complexes of diphosphazane dioxides". J. Chem. Soc. Dalton Trans. 1995, 2991-2997.

31. Rammo, N. N.; Hamid, K. R.; Ibrahim, T. K., "Preparation, characterization and crystal structure of 4,4'-bipyridinium nitrate trinitratodioxo-uranium(VI) and 4,4'-dipyridinium diaqua hexanitrato-thorate(IV)". J. Alloys Compd. 1994, 210, 319-324.

32. Rammo, N. N.; Hamid, K. R.; Khaleel, B. A., " Synthesis and crystal structure analysis of 4,4'-dipyridinium 4,4'-dipyridinium(II)nitrate hexanitratothorate(IV)

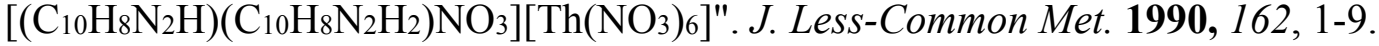

33. Goodgame, D. M. L.; Menzer, A. M.; Menzer, S.; White, A. J. P.; Williams, D., " Influence of the metal ion on the structures of complexes formed by the extended reach ligand $N, N^{\prime}-\mathrm{m}-$ phenylenedimethylenebis(pyridin-2-one)". Inorg. Chim. Acta. 2003, 355, 314-321.

34. Alcock, N.; Esperås, S.; Bagnall, K. W.; Hsian-Yun, W., "Trimethylphospine oxide complexes of thorium and uranium tetranitrates; crystal structures of ten- and twelve-coordinate complex ions, bis[trinitratotetrakis(trimethylphosphine oxide)thorium(IV)] hexanitratothorate(IV) and tetraphenylphosphonium pentanitratobis(trimethylphosphine oxide)thorate (IV)". J. Chem. Soc. Dalton Trans. 1978, 638-646.

35. English, R. P.; du Preez, J. G. H.; Nassimbeni, L. R.; van Vuuren, C. P. J., "Structure and solution behaviour of $\mathrm{Th}\left(\mathrm{NO}_{3}\right) 4-2,6,7$ tdpo: bis \{trinitratotetrakis[tris(dimethylamido)phosphine]oxide thorium $\}$ hexanitratothorate". S. Aft. J. Chem. 1979, 32, $119-125$. 
36. Zhao, M.-X.; Zhu, W.-X.; Ma, S.-L.; Yuan, D.-Q.; Wang, Z.-M., "Synthesis and Crystal Structure of a Thorium( ) Nitrate Complex with Phosphinoxide[- $\left.\mathrm{CH}_{2} \mathrm{P}(\mathrm{O}) \mathrm{Ph}_{2}\right]$-substituted Calix[4]arene". Acta Chim. Sinica 2004, 62, 1260-1264.

37. Cheng, J.-Y.; Dong, Y.-B.; Ma, J.-P.; Huang, R.-Q.; Smith, M. D., "Two-dimensional hydrogen-bonded networks based on bent oxadiazole bridging organic spacers". Inorg. Chem. Commun. 2005, 8, 6-8.

38. Bowen, S. M.; Duesler, E. N.; Paine, R. T., "Synthesis and crystal and molecular structure of a [diethyl ( $N, N$-diethylcarbamyl)methylenephosphonate]thorium nitrate complex". Inorg. Chem. 1982, 21, 261-265.

39. Agarwal, D. D.; Srivastava, S.; Chadha, P., "Synthesis, characterization and catalytic behaviour of thorium peroxo complexes". Polyhedron 1990, 9, 1401-1403.

40. Agarwal, D. D.; Agarwal, S. C.; Sharma, L., "Thorium peroxo complexes catalysed oxidation of olefins using tert-butyl hydroperoxide". J. Indian Chem. Soc. 1992, 69, 227-231. 